\title{
RIVALRY OR ALLIANCE?: THE RELATIONSHIP BETWEEN HYPERBOLE AND LITERAL LANGUAGE
}

\author{
Laura Cano Mora
}

Universitat de València

1.canomora@gmail.com

\begin{abstract}
This paper focuses on the relationship between neighbouring literal and figurative expressions, a much under-researched area in figurative language theories. Traditionally it has been assumed that language is used figuratively when a literal expression would be inadequate, thus supporting the view that figurative and literal language replace or substitute each other. In order to question this view and to explore this relationship, a group of hyperbolic adverbs extracted from the British National Corpus and used in naturallyoccurring speech was examined. The results show that hyperbole and literal comments seem to extend and complement, rather than replace, each other. This complementation is often achieved through paraphrase or clarification of a preceding remark, whether literal or exaggerated. The analysis also seems to suggest that if speakers need to add some information the most common pattern is a hyperbole followed, rather than preceded, by a literal expression.
\end{abstract}

KEY WORDS: adverbs, hyperbole, literal language, corpus linguistics and conversational analysis.

\section{RESUMEN}

El presente artículo se centra en el estudio de la relación entre expresiones literales y figuradas adyacentes, cuestión rara vez investigada en las teorías del lenguaje figurado. 
Tradicionalmente se ha creído que los hablantes utilizamos las figuras cuando el lenguaje literal resulta inadecuado, reafirmando así la idea de que el lenguaje literal y figurado se sustituyen el uno al otro. Con el fin de cuestionar esta visión y explorar dicha relación examinamos un grupo de adverbios hiperbólicos usados en conversaciones reales extraídas del British National Corpus. Los resultados indican que la hipérbole y el uso literal del lenguaje parecen complementarse en lugar de reemplazarse. Con frecuencia dicha complementariedad se consigue a través de la paráfrasis o clarificación de un comentario previo, ya sea literal o exagerado. El análisis a su vez parece sugerir que cuando el hablante siente la necesidad de añadir información el patrón más común es una hipérbole seguida, en lugar de precedida, de una expresión literal.

Palabras clave: adverbios, hipérbole, lenguaje literal, lingüística de corpus y análisis conversacional.

Certainly, then, ordinary language is not the last word: in principle it can everywhere be supplemented and improved upon, and superseded. John L. Austin (Philosophical Papers, 1979)

\section{INTRODUCTION}

Since antiquity figures of speech have been widely studied in rhetoric, although contemporary rhetoric has rather tended to relegate their study to the domain of literary criticism. However, since the 1980s, there has been a renewed interest in figurative language not only in literary studies but also in other fields of research, such as linguistics (e.g. Sadock, 1993; Mayoral, 1994), pragmatics (e.g. Dascal and Gross, 1999; Carston, 2002; Carston and Wearing, 2011) and cognitive psychology (e.g. Fussell and Moss, 1998; Link and Kreuz, 2005; Herrero, 2009). In fact, research on figuration has emerged as a new and distinct discipline, that of figurative language studies. Most of this interest, however, has been directed at explaining how figures are comprehended, given their nonliteral nature (e.g. Gibbs, 1994; Giora, 1997; Ruiz de Mendoza and Santibáñez, 2003). Since the bulk of studies has almost invariably concentrated on the reception process, it is not surprising that nowadays a crucial limitation in figurative language theories is the production process.

This paper focuses on hyperbole, a long neglected figure despite its pervasiveness in everyday speech. It aims to examine the relationship between neighbouring or adjacent literal and hyperbolic expressions as a way of conveying exaggeration. It has traditionally been assumed that language is used figuratively when a literal expression would be inadequate. This paper questions this idea in favour of a more interactive view of literal and non-literal language. This type of relationship has never been mentioned in the case of hyperbole and has only been briefly discussed for other figurative language forms (e.g. Drew and Holt, 1998; Fussell and Moss, 1998). 


\section{RESEARCH ON HYPERBOLE}

Within figurative language theories, metaphor and irony have been considered the master tropes and have received the greatest attention. As a result, other nonliteral forms have been largely ignored. This explains why very little is known about hyperbole. However, Kreuz et al. (1996), after studying eight main forms of nonliteral language in a literary corpus, adduced empirical evidence of its pervasiveness by showing that after metaphor, hyperbole was the most common figure. In terms of co-occurrence, exaggeration also proved to be by far the trope that most often interacted with other indirect forms.

Although hyperbole has been, since late antiquity, one of the many figures discussed within rhetoric, the emphasis has traditionally been on defining, classifying and illustrating overstatement. In other disciplines no serious attention has been paid to hyperbole, probably because it has generally been regarded as a classic trope whose study belongs to the domain of rhetoric. Most of the empirical work on exaggeration involves comparisons of frequency and use in different cultures (e.g. Spitzbardt, 1963; Cohen, 1987; Edelman et al., 1989). Besides these crosscultural studies, most interest has been directed at explaining the cognitive processes involved in hyperbole understanding (e.g. Winner et al., 1987; Gibbs et al., 1993; Colston and O'Brien, 2000; Leggitt and Gibbs, 2000). Much of this literature can be found in the field of psycholinguistics and subsumed within theories of humour or irony. There are only a few studies that have not totally disregarded the production process of hyperbole. However, although they address the pragmatic functions fulfilled by overstatement, it is always in combination with other figurative language forms such as irony and understatement in order to contrast the extent to which they accomplish the same discursive goals (e.g. Roberts and Kreuz, 1994; Sell et al., 1997; Colston and Keller, 1998; Colston and O’Brien, 2000).

\section{Methodology}

\subsection{Corpus description}

In order to explore the relationship between hyperbole and literal language in everyday conversation, a corpus of naturally-occurring spoken fragments containing hyperbolic adverbs was taken from the British National Corpus (BNC henceforth) and subjected to analysis. The BNC is a collection of over 4000 samples, totalling over 100 million words, of modern British English, both spoken and written, stored in electronic form. However, the focus was on oral discourse since most research on hyperbole has been conducted in written language. This choice was aimed at counterbalancing the scarcity of studies addressing hyperbole in «authentic» everyday talk since rhetorical scholars have often listed striking phrases from earlier writers, especially poets, as examples of rhetorical figures. On the other hand, the bulk of psycholinguistic research over the last thirty years has utilised artificial texts as stimulus materials. Only recently have some scholars started to focus on naturally-occurring spoken hyperbole (e.g. McCarthy and Carter, 2004; Cano Mora, 2011). 
The benefits of a corpus-based study, as McCarthy and Carter (2004) have shown, are manifold. If a referential trope such as hyperbole can only be understood in context, then a corpus offers many different contexts brought together under one body of data. If certain semantic fields are regularly exploited for hyperbole, then the corpus enables verification of such tendencies, or equally, may reveal gaps in the fields where potential items are not exploited. In addition, a corpus-based study will reveal that hyperboles are not one-off lexico-grammatical items: discourse-syntactic strategies such as repetition and clustering of hyperbolic items, paraphrase and clarification of exaggerated remarks as well as self-repair mechanisms suggest that hyperboles need to be examined over turn-boundaries and within the constraints of placement and sequencing of conversational analysis.

\subsection{Research items}

Defining and classifying figures of speech have been among the most important tasks of rhetoricians and grammarians for more than two millennia. This explains the wide range of definitions that can be found in the literature on exaggeration. Definitions of hyperbole in rhetoric generally respond to the etymology of the term in Greek and Latin, which refers to the notion of excess and extremity. I will follow the distinction found in classical rhetoric whereby hyperbole is twofold: auxesis (i.e. exaggerated amplification) and meiosis ${ }^{1}$ (i.e. exaggerated reduction). Mayoral (1994) deserves special mention for making explicit reference to the evaluative or qualitative dimension of the trope whereby we exaggerate praise or criticism. More recent definitions of hyperbole tend to be goal-oriented and focus on the use of this figure for emphasis (e.g. Cuddon, 1998) or for a particular effect, such as humour, affect, etc.

The main problem with the existing definitions is that they are too generic and do not clearly distinguish this trope from other related figures of speech and disproportion. Irony, for example, may also involve an element of extremity in saying the opposite of what the speaker means and may also be used to produce a humorous or comic effect.

In order to distinguish hyperbole from other figures, the following definition will be adopted:

A figure whereby the quantity or quality of an objective fact is, whether purposely or inadvertently, subjectively inflated or deflated in varying degrees but always to excess in a conventional or creative utterance which listeners do not normally interpret literally or perceive as a lie. (Cano Mora, 2011: 38)

Given this definition, hyperbole needs to be seen as a broad term comprising a wide range of different forms of excess and extremity including extreme case formulations

${ }^{1}$ It seems that understatement is frequently confused with meiosis or hyperbole that exaggerates a smaller-than-expected quantity or quality. Cano Mora (2011: 35) formulates the difference between these two distinct figures as follows: «hyperbole describes moderate situations in the real world as extreme, whereas understatement describes extremes situations in the real world as moderate». She also claims that hyperbole and understatement significantly differ in communicative purpose: hyperbole serves to intensify or emphasise whereas understatement is used to mitigate. 
(cf. Pomerantz, 1986; Edwards, 2000; Norrick, 2004), auxesis, meiosis, exaggeration and overstatement.

For the purposes of this paper hyperbolic adverbs -and by extension the utterances were they were embedded- were the object of analysis. The focus was on adverbs because other grammatical categories or word classes, especially expressions of quantification and adjectives, have been the object of extensive research in connection to hyperbole. Here I shall consider a sample of adverbs which belong to circumscribed semantic fields and which show tendencies to be used hyperbolically.

The typology of hyperbolic adverbs here presented falls into two domains: evaluative adverbs (within the exalt-condemn scale) and quality adverbs (within the enlargediminish scale). The typology resembles, with slight variations, Bolinger's (1972) classification of adverbial intensification ${ }^{2}$. All forms of exaggeration can be semantically classified into one of the core semantic fields examined in Table 1.

Table 1. Typology of semantic fields for hyperbolic adverbs

\begin{tabular}{|c|c|}
\hline Evaluation & Quality \\
\hline & Size \\
Positive evaluation & Frequency \\
& Psychotic or abandonment \\
Negative evaluation & Strength or intensity \\
& Singularity \\
& Veracity or credibility \\
\hline
\end{tabular}

The hyperbolic adverbs selected for analysis were chosen because they were all extreme forms of exaggeration. It was also required that (i) they showed a strong tendency to be used hyperbolically and (ii) were representative enough of the aforesaid semantic categories. In any case, any list of adverbs has to be viewed as a sampling rather than a catalogue because the list of hyperbolic adverbs is too open-ended.

Table 2 provides a detailed list of the hyperbolic adverbs subjected to study.

Table 2. Hyperbolic adverbs examined in the BNC spoken corpus

\begin{tabular}{|c|l|}
\hline \multirow{2}{*}{ Evaluation } & $\begin{array}{l}\text { Positive evaluation: excellently, fantastically, magnificently, delightfully, marvellously } \\
\text { Negative evaluation: abominably, dismally, disastrously, pitifully, horribly }\end{array}$ \\
\hline \multirow{5}{*}{ Quality } & Size: abysmally, astronomically, immensely, infinitely, universally \\
& Frequency: unceasingly, incessantly, endlessly, instantly, perpetually \\
& $\begin{array}{l}\text { Psychotic/abandonment: pathologically, feverishly, frantically, crazily, madly } \\
\text { Strength/intensity: savagely, fiercely, mortally, deadly, totally }\end{array}$ \\
& Singularity: phenomenally, spectacularly, outstandingly, extraordinarily, exceptionally \\
& Veracity/credibility: undoubtedly, unquestionably, undeniably, incredibly, unbelievably
\end{tabular}

${ }^{2}$ Bolinger (1972: 242) distinguished 10 categories in his classification of adverbial intensifiers: size (e.g. monstrously), strength (e.g. heartily), impact (e.g. awesomely), abandonment (e.g. deliriously), tangibility (e.g. visibly), evaluation (e.g. outrageously), consistency (e.g. solidly), irremediability (e.g. woefully), singularity (e.g. exceptionally) and purity or veracity (e.g. 100\%). To avoid semantic overlapping, I grouped strength, impact, tangibility, consistency and irremediability into a single category because they all refer somehow to the strength or intensity of some action or event. 
A total amount of 40 different hyperbolic adverbs -five per semantic group- was analysed. Fifteen different hyperbolic samples, totalling 120, were examined per semantic field. When the BNC provided several occurrences of the same adverb but in different contexts they were selected at random, provided that they were used hyperbolically.

Some of these adverbs, such as abysmally or infinitely, seem more hyperbolicallyprone than other adverbs, such as pathologically or universally, which present both a literal and a hyperbolic reading. The following examples may serve to illustrate this duality: the first reading is literal, while the second is hyperbolic. However, only instances of adverbs with a hyperbolic reading were subjected to analysis in this paper.

\section{(1) Text HE2}

Speaker 1: Children are always for analysis, usually by their parents, they don't usually come of their... So the analysts found they couldn't use free association with children. What they could use was defence analysis. So for example, if you saw a child, who was pathologically independent, wouldn't form emotional attachments or dependencies on other people of the way the child wanted it. The analyst might conclude, well, why is this defence structure excessive independence present in this child? A good suggestion might be, in the past this child has suffered a loss of some figure it was dependent on, and has compensated by becoming highly independent.

\section{(2) Text KBF}

Speaker 1: No. I said, you know, I did some extra hours for you.

Speaker 2: Mm, mm

Speaker 1: Oh, yes, he said I've worked it out those extra hours. I've paid you for them but I thought you actually worked for them for nothing and I've just given you a bonus

Speaker 2: Oh, good god!

Speaker 1: and er

Speaker 2: This man is pathologically mean!

Speaker 1: Well, the these

Speaker 2: Pathologically mean!

Speaker 1: these decorators just could not believe how

Speaker 2: No, no.

Speaker 1: they were just so amazed!

\subsection{Procedure}

In order to explore the relationship between adjacent literal and hyperbolic expressions, I will concentrate on those contributions where the speaker uses an expression and shortly afterwards adds another one of a different nature -whether literal or containing a hyperbolic adverb- but with a similar meaning and within the same turn or subsequent turns. This means that a discourse analysis approach has been here adopted, with overstatement being studied beyond turn-boundaries and within the constraints imposed by the turn-taking system and the sequential organisation of conversation. It also implies that longer fragments or stretches of conversation were examined rather than isolated instances of hyperbole. 


\section{RESUlts AND DISCUSSION}

As for the analysis, out of 120 hyperbolic adverbs only 30 -representing $25 \%$ of the items examined- appear in combination with literal language. Within this framework two antithetical patterns can be clearly distinguished depending on whether hyperbole is preceded or followed by literal expressions.

Table 3. Occurrences, percentages and combination types for hyperbole

\begin{tabular}{|c|c|c|}
\hline Combination types & Occurrences & Percentage \\
\hline Literal + hyperbolic remarks & 12 & $40 \%$ \\
\hline Hyperbolic + literal remarks & 18 & $60 \%$ \\
\hline
\end{tabular}

Sometimes the speaker produces a literal version that depicts the actual state of affairs and then upscales one of the meaning dimensions of the utterance thus giving rise to an overstated description. There are 12 instances of this pattern in the BNC data, which represent $40 \%$ of the combinations examined. The fragment below -where the hyperbolic adverb appears in bold, the overstated utterance in italics and underlined the literal remark- may serve to illustrate the case.

\section{(3) Text KP1}

Speaker 1: Fast asleep and then he'd move his hands, do you know erm like in meditation people, when they're meditating and their minds are away, and the bodies are calm and relaxed, it was like than, then he'd go back into his sleep

Speaker 2: Yeah

Speaker 1: and then he woke up, his, his eyes opened from this, he was actually asleep and his, he woke up from it, not with a start, but the, it's, he woke up very quickly, instantly and he just started to do things.

Speaker 2: What do, what age do you think he is?

Speaker 1: Oh, well, in his seventies, touching eighty.

This is consistent with Roberts and Kreuz's (1994) finding that people report using figures, especially rhetorical questions, similes, metaphors and hyperbole to clarify their meanings. Similarly, Sell et al. (1997) have shown that a common function for hyperbole, rhetorical questions and idioms is clarification.

At other times, the speaker initially produces an overstated account and then alters the magnitude involved in the utterance to make it fit reality. This is the most recurrent pattern, with 18 occurrences, in the BNC excerpts and it represents $60 \%$ of the combinations analysed. Let us take the following excerpt where the literal utterance suggests that the doctor did not in fact prescribe the tablets instantaneously but took some time to analyse the patient's symptoms and to listen to the narration of her loss. Note that instantly is an example of meiosis or a hyperbole that exaggerates a smaller-than-expected quantity.

\section{(4) Text J8J}

Speaker 1: I mean recently I had about, er went through a bereavement, lost Speaker 2: Yep. 
Speaker 1: my brother who I was very close to, I went to the doctor and, instantly he, pres, er prescribed Tamazapam tablets for me, knowing that I myself am a single parent so I have a responsibility.

Speaker 2: Mm.

Speaker 1: I've my daughter to look after. Didn't ask me anything! Just looked at me, saw how I was, prescribed the tablets.

Excerpt 4 shows that figurative expressions can also set the stage for later details, explaining in a literal way what is meant by the use of an exaggeration. This seems to suggest that literal language too is used to clarify or explain indirect or non-literal language forms.

The matter of a speaker selecting a literal expression in preference to a figurative way of saying or describing something is particularly visible in the case of self-repairs, when the speaker changes what was going to be an exaggerated account and replaces it with a literal remark. Extract 5 is an example of such self-repair mechanisms.

\section{(5) Text HV1}

Speaker 1: Nicola, you suffered some of the side effects that we've been hearing about tonight, and then things got really bad. How bad did they get?

Speaker 2: I was only on the drug for seven days and by the seventh day, I'd suddenly turned into some sort of maniac. I became incredibly vi er I had violent feelings erm, I wanted to go out on the street and rampage. If I'd had a gun I would have gone out and shoo shot out the whole neighbourhood. Erm and really the only way I thought that I could prevent myself from doing anything like that was to kill myself in a very violent way.

However, in accordance with Drew and Holt's (1998) findings, self-repairs involving the substitution of a literal for a figurative description were also found in our data. Here the speaker starts to produce a literal version, but then does a self-repair which replaces that account with an overstated description.

\section{(6) Text F7T}

Speaker 1: It's much big it's a, it's it's a, it's an incredibly wide sample opinion poll. Because we're talking millions of voters yeah. If you get a forty percent turn out in a local elect within England yeah? If you get a forty percent turn out in England and Wales, we're talking many millions of voters. And when you think that the biggest opinion poll samples are what five, ten thousand? So it's pretty, it is a much more accurate guide than any opinion poll.

On the other hand, the results seem to suggest that the relationship between exaggerated and literal expressions can be defined as twofold: complementation and substitution.

Table 4. Number, percentage and type of relationship within combinations

\begin{tabular}{|c|c|c|}
\hline Type of relation within combinations & Occurrences & Percentage \\
\hline Complementation & 27 & $90 \%$ \\
\hline Substitution & 3 & $10 \%$ \\
\hline
\end{tabular}


Complementation refers to situations where the hyperbolic and literal tokens expand, extend and add to each other. With 27 occurrences, this is by far the most common pattern in the data examined. This complementation is often achieved through clarification or through paraphrase of a previous utterance, whether literal or exaggerated.

It seems that speakers complement indistinctly via clarification or paraphrase since roughly equal numbers of both patterns were found in the BNC data examined: 14 hyperbolic adverbs involved paraphrase and 13 referred to some form of clarification.

Extract 7 exemplifies how through clarification speakers explain, describe or detail some situation.

\section{(7) Text KS1}

Speaker 1: What sort of people would you involve in this meeting? I mean, there's a lot of voluntary organisations who are working in this field, I don't know how you would just make sure you got them all. The resources are pitifully small. I mean, I'm involved in doing some statistics for Windmill House, the probation service, and we've found that the sixteen-to-eighteen-year-old provision in the city is very, very small. I'm sure it's the same for many of the other groups who've got problems. But, erm I hope you involve all those sort of organisations in your discussions.

On the other hand, in using paraphrase the speaker rewords, restates or repeats some idea which has been mentioned before, as in the fragment below.

\section{(8) Text KP8}

Speaker 1: so you're not working this weekend, it's the next weekend you're working?

Speaker 2: No, I swapped erm, I should be working this weekend but

Speaker 1: Yes.

Speaker 2: erm, I swapped with erm Bernie.

Speaker 1: Ah!

Speaker 2: Erm and it's worked out marvellously.

Speaker 1: Aha.

Speaker 2: Er, unin unintentionally er, because I have my days off Thursday, Friday next week

Speaker 1: Yes.

Speaker 2: which are the sa same days as the school's off for their

Speaker 1: Oh!

Speaker 2: erm, half term.

Speaker 1: Oh good!

Speaker 2: And I've got this weekend off, not having to work when it's Chris birthday [...] It's worked out well for both us.

The opposite pattern is substitution. It is when the hyperbolic and literal tokens replace, supplant or supersede each other. This substitution takes the form of self-repairs as shown in examples 5 and 6 above. It is when the speaker either changes what was going to be an exaggerated account and replaces it with a literal remark or substitutes hyperbole for a literal depiction of reality.

As shown in table 4 above, these substitutions or self-repair mechanisms are rare in our transcripts, thus demonstrating that literal and figurative language complement 
and further extend, rather than replace, each other. Hence, the relationship between neighbouring literal and hyperbolic expressions in the data examined can be defined as complementary rather than competitive.

\section{ConClusion}

By concentrating on the relationship between hyperbole and literal language this paper has addressed an aspect related to the production of figures, a much under-researched area of study within figurative language theories. Thus, this paper adheres to the view that the study of the reception and cognitive aspects of figures of speech should be complemented by research on their process of production.

In examining the relationship between literal language and exaggeration, we have to distinguish between complementation and substitution. Although it has typically been assumed that language is used figuratively when a literal expression would be inadequate, a rather different picture emerges from the results of our analysis. The BNC data examined suggest that speakers do not normally use hyperbolic items in lieu of literal ones, but rather in addition to them. Hyperbole and literal comments seem to reinforce and complement, rather than replace, each other. Instead of competing with or substituting the preceding version, it seems that literal language and hyperbole clarify, explain and add to each other. This conclusion questions the traditional and long-established idea of exclusion in favour of a more interactive view of literal and non-literal language forms.

Complementation, which involves some expansion or repetition of sense, is employed to ensure that listeners get across the force of the speaker's utterance, whether literal or figurative. Indeed, it has been argued that «a figurative expression, $E$, may be conjoined with an expression whose literal content is similar to the potential figurative effect of $E$ and no redundancy should result» (Sadock, 1993: 52-3). It should be mentioned, though, that compared to hyperbole, «literal paraphrases have less emphasis, are less vivid, less affectively tuned, and possess less variety of possible nuances of interpretation» (Cacciari, 1998: 143). This complementation is often achieved through clarification or through paraphrase of a preceding utterance, whether literal or exaggerated. It seems that in terms of complementation both strategies are equally important. This, together with the scarce number of self-repairs, goes to show that hyperbole is not simply a substitution of literal language forms.

On the other hand, the most common pattern found in the data examined is a hyperbole followed by literal comments. That is to say, speakers rephrase or clarify via literal rather than via overstated remarks. A possible explanation for the higher use of literal language forms after overstatement may be attributed to the greater risk of misunderstanding that speakers undertake when they speak figuratively or indirectly. In using hyperbole it is more likely that readers or hearers misinterpret my words so the use of a subsequent literal paraphrase to leave no doubt about the meaning I am trying to convey seems only logical.

But then how can we explain the opposite pattern? How is that speakers also use hyperbole to paraphrase a literal remark they have previously uttered? Given that in our data most exaggerations are not connected to other literal language forms, it is more rea- 
sonable to presume that it is only when speakers feel their words can be misunderstood that they resort to complementation, whether literal or exaggerated. It often occurs when the communicative situation is defective or when the speaker is particularly anxious to ensure communicative success. Furthermore, the fact that $75 \%$ of the hyperbolic adverbs and utterances examined appear in isolation, without the aid of literal language forms, shows that there is little risk of misunderstanding when engaged in hyperbole.

Finally, this paper has shown that hyperboles are not one-off lexico-grammatical items. Discourse-syntactic strategies such as paraphrase, clarification and self-repairs of or by means of hyperbolic items suggest that hyperboles need to be examined not in isolation as has traditionally been done but over turn-boundaries and within the constraints of placement and sequencing of conversational analysis. As Cornbleet and Carter (2001: 64) note: «it's quite wrong to take naturally occurring speech and isolate utterances because a great deal of the language interrelates and interweaves across longer stretches of the exchange».

\section{REFERENCES}

Austin, John L. (1979). Philosophical Papers, 3rd edition, Oxford, Clarendon Press, p. 185.

Bolinger, Dwight L. (1972). Degree Words, The Hague, Mouton, p. 242.

CACCIARI, Christine (1998). «Why Do We Speak Metaphorically? Reflections in Thought and Language». In Katz, Albert N. et al. (eds.). Figurative Language and Thought, Oxford, Oxford University Press, 119-157.

Cano Mora, Laura (2011). This Book Will Change Your Life! Hyperbole in Spoken English, Valencia, Publicacions de la Universitat de València, p. 38.

CARston, Robyn (2002). Thoughts and Utterances: The Pragmatics of Explicit Communication, Oxford, Basil Blackwell, p. 16.

Carston, Robyn and Catherine Wearing (2011). Metaphor, Hyperbole and Simile: A Pragmatic Approach, Language and Cognition 3(2), 283-312.

Cohen, Raymond (1987). «Problems of Intercultural Communication in Egyptian-American Diplomatic Relations», International Journal of Intercultural Relations 11, 29-47.

Colston, Herbert L., and Shauna B. Keller (1998). «You'll Never Believe This: Irony and Hyperbole in Expressing Surprise», Journal of Psycholinguistic Research 27, 499-513.

Colston, Herbert L. and Jennifer O’Brien (2000). «Contrast of Kind Versus Contrast of Magnitude: The Pragmatic Accomplishments of Irony and Hyperbole», Discourse Processes 30, 179-199.

Cornbleet, Sandra and Ronald A. CARTER (2001). The Language of Speech and Writing, London, Routledge, p. 64.

Cuddon, John A. (1998). A Dictionary of Literary Terms and Literary Theory, London, Penguin, p. 406.

Dascal, Marcelo and Alan G. Gross (1999). «The Marriage of Pragmatics and Rhetoric», Philosophy and Rhetoric 32, 107-130.

Drew, Paul and Elisabeth Holt (1998). «Figures of Speech: Figurative Expressions and the Management of Topic Transition in Conversation», Language in Society 27, 495-522.

Edelman, Robert J. et al. (1989). «Self-Reported Expression of Embarrassment in Five European Cultures», Journal of Cross-Cultural Psychology 20, 357-371.

EDWARDS, Derek (2000). «Extreme Case Formulations: Softeners, Investment, and Doing Nonliteral», Research on Language and Social Interaction 33(4), 347-373. 
Fussell, Susan R. and Mallie M. Moss (1998). «Figurative Language in Emotional Communication». In Fussell, Susan R. and Roger J. Kreuz (eds.). Social and Cognitive Approaches to Interpersonal Communication, Mahwah, NJ, Lawrence Erlbaum Associates, 113-143.

GiBBs, Raymond W. (1994). The Poetics of Mind: Figurative Thought, Language and Understanding, Cambridge, Cambridge University Press.

- et al. (1993). «Literal Meaning and Figurative Language», Discourse Processes 16, 387-403.

Giora, Rachel (1997). «Understanding Figurative and Literal Language: The Graded Salience Hypothesis», Cognitive Linguistics 8, 183-206.

Herrero Ruiz, Javier (2009). Understanding Tropes: At the Crossroads between Pragmatics and Cognition, Berlin, Peter Lang.

Kreuz, Roger J. et al. (1996). «Figurative Language Occurrence and Co-Occurrence in Contemporary Literature». In Kreuz, Roger J. and Mary S. Macnealy (eds.). Empirical Approaches to Literature and Aesthetics, Norwood, NJ, Ablex Publishing Corporation, 83-97.

LegGitT, John S. and Raymond W. GibBS (2000). «Emotional Reactions to Verbal Irony», Discourse Processes 29, 1-24.

Link, Kristen E. and Roger J. Kreuz (2005). «Do Men and Women Differ in Their Use of Nonliteral Language When They Talk about Emotions?». In Colston, Herbert L. and Albert N. Katz (eds.). Figurative Language Comprehension: Social and Cultural Influences, Mahwah, NJ, Lawrence Erlbaum Associates, 153-180.

Mayoral, José A. (1994). Figuras retoricas, Madrid, Editorial Síntesis, p. 243.

Mccarthy, Michael J. and Ronald A. Carter (2004). «"There's Millions of Them": Hyperbole in Everyday Conversation», Journal of Pragmatics 36, 149-184.

Norrick, Neal R. (2004). «Hyperbole, Extreme Case Formulation», Journal of Pragmatics 36(9), 1727-1739.

Pomerantz, Anita (1986). «Extreme Case Formulations: A Way of Legitimizing Claims», Human Studies 9, 219-229.

Roberts, Richard M. and Roger J. Kreuz (1994). «Why Do People Use Figurative Language?», Psychological Science 5, 159-163.

Ruiz de Mendoza, Francisco J. and Francisco Santibáñez (2003). «Content and Formal Cognitive Operations in Construing Meaning», Italian Journal of Linguistics 15(2), 293-320.

SADOCK, Jerrold M. (1993). «Figurative Speech and Linguistics». In Ortony, Andrew (ed.). Metaphor and Thought, Cambridge, Cambridge University Press, 42-57.

Sell, Marie A. et al. (1997). «Parents' Use of Nonliteral Language with Preschool Children», Discourse Processes 23, 99-118.

SPITZBARDT, Harry (1963). «Overstatement and Understatement in British and American English», Philologica Pragensia 6, 277-286.

Winner, Ellen et al. (1987). «Making Sense of Literal and Nonliteral Falsehood», Metaphor and Symbolic Activity 2, 13-32. 